\title{
The construction and testing of an acoustic energy harvester consisting of a Helmholtz resonator and a loudspeaker
}

\author{
Ikhsan Setiawan and Mulaiyinatus Sifa \\ Physics Department, Faculty of Mathematics and Natural Sciences, Universitas Gadjah Mada \\ Sekip Utara BLS 21 Yogyakarta 55281 Indonesia \\ E-mail: ikhsan_s@ugm.ac.id
}

Received 13 January 2020, Revised 8 February 2020, Published 29 March 2020

\begin{abstract}
Sound energy is all around but not properly utilized despite being a source of electricity. This research was conducted to construct and test an acoustic energy harvester consisting of a Helmholtz resonator and a loudspeaker. The resonator cavity was made of $10 \mathrm{~mm}$-thick cube-shaped acrylic plates with an inner side length of $300 \mathrm{~mm}$ while its neck was made of PVC (polyvinyl chloride) pipes with an inner diameter of $55 \mathrm{~mm}$ and three length variations at $50 \mathrm{~mm}, 70 \mathrm{~mm}$, and $90 \mathrm{~mm}$. A 6-inch subwoofer loudspeaker was mounted on the resonator back wall facing the cavity with its terminals connected to a 100 -ohm load resistor. The sound waves entering the resonator cavity through the neck were converted into the alternating electric current flowing through the resistor. The test was conducted experimentally by exposing the harvester to sound waves at a maximum sound pressure level (SPL) of $100 \mathrm{~dB}$ and frequency variations from $25 \mathrm{~Hz}$ to $200 \mathrm{~Hz}$. The root-mean-square (rms) voltages across the resistor were measured to calculate the output rms values for electric power. The results showed seven spectrum peaks which appeared at frequencies of $31 \mathrm{~Hz}, 37 \mathrm{~Hz}, 41 \mathrm{~Hz}, 49 \mathrm{~Hz}, 58 \mathrm{~Hz}, 73 \mathrm{~Hz}$, and $82 \mathrm{~Hz}$. Moreover, a shorter neck was also observed to have produced higher output power as indicated by the highest value of $2.75 \mathrm{~mW}$ obtained by using a $50 \mathrm{~mm}$-long resonator neck at $37 \mathrm{~Hz}$ frequency and $100 \mathrm{~dB}$ SPL. These findings showed the acoustic energy harvester used to be effective due to its ability to produce electricity even at low frequencies below $100 \mathrm{~Hz}$.
\end{abstract}

Keyword: Acoustic energy harvester, Helmholtz resonator, loudspeaker, sound energy, electricity

\section{Introduction}

In the recent decade, more researchers are interested in researching and developing the capability and performance of harvesting energy from the environment (Choi et al., 2009; Yuan et al., 2019; Khan \& Izhar, 2015; Pillai \& Deenadayalan, 2004). For example, environmental noise is acoustic energy which can be harvested as ambient energy. This process is known as the Acoustic Energy Harvesting (AEH) and defined as the conversion of continuous and intense acoustic waves from the environment into 
electricity using an acoustic transducer and resonator (Pillai \& Deenadayalan, 2004). The electric power produced by AEH devices is, however, typically small ranging between picowatts to milliwatts with only a few reaching tens of milliwatts (Khan \& Izhar, 2015; Pillai \& Deenadayalan, 2014; Setiawan, 2019). Therefore, one of their applications is to energize low-power sensors in Wireless Sensor Networks (WSN) in remote areas using piezoelectric transducers (Choi, 2009; Khan \& Izhar, 2015; Zhou et al., 2014). Moreover, even though the power usually acquired is low, the massive application of these AEH devices, for example, in an array arrangement produces high accumulated electric power capable of being stored in an energy storage unit such as a supercapacitor (Yuan et al., 2019; Pillai \& Deenadayalan, 2014).

It is usually possible to find wasted and disturbing environmental noise or sound energy at a relatively high level in big cities with those on a highway at a crowded or busy time having up to $90 \mathrm{~dB}$ Sound Pressure Level (SPL) at approximately $10 \mathrm{~m}$ distance from the center of the noise (Pillai \& Deenadayalan, 2014). There is a possibility of finding higher levels in some industrial plants producing noise at approximately 100 to $136 \mathrm{~dB}$ SPLs (Khan \& Izhar, 2015). Moreover, it is also possible to receive noise estimated to be $140 \mathrm{~dB}$ at $100 \mathrm{~m}$ from jet engines of an aircraft during take-off (Pillai \& Deenadayalan, 2014). These facts show the amount of energy wasted around us and its potential to be harnessed as an environmentally-friendly alternative energy source. It is, however, important to note that environmental noise is dominantly in a low-frequency region. Therefore, AEH devices operating at low frequencies do not only have the ability to produce electricity but also to reduce the noise.

AEH devices, also called acoustic energy harvesters, generally consist of an acoustic transducer, a resonator, and an energy storage unit. The acoustic transducer can be a piezoelectric plate or membrane or even a magnet attached to a membrane designed to vibrate near a coil when subjected to sound waves (Choi et al., 2009; Yuan et al., 2019; Khan \& Izhar, 2015; Pillai \& Deenadayalan, 2004). Moreover, it is also possible to o convert sound energy into electrical energy using a loudspeaker. In this case, the incoming sound waves move the loudspeaker's coil back and forth in a magnetic field to induce an alternating electric current in the coil. This method has, however, only been applied in thermoacoustic electricity generators which convert thermal energy into sound energy and then into electric power (Yu et al., 2010; Kang et al., 2015). The resonator used in an $\mathrm{AEH}$ device collects sound energy and increases the amplitude of the sound waves at certain frequencies to cause vibration in the acoustic transducer. Some examples of this include Helmholtz resonator, quarter-wavelength straight resonator, and half-wavelength straight resonator (Sohn \& Park, 2011).

An acoustic energy harvester consisting of a 6-inch loudspeaker and a quarterwavelength resonator was recently produced and the best results obtained were the production of rms electrical power at $20.7 \mathrm{~mW}$ using a resonator with $133 \mathrm{~cm}$ length exposed by the sound of at $105 \mathrm{~dB}$ SPL and $92 \mathrm{~Hz}$ frequency (Setiawan, 2009). This is actually very good considering the electric power generated was in the highest order of results previously obtained which were usually in the order of tens of milliwatts (Khan \& Izhar, 2015; Pillai \& Deenadayalan, 2014). However, the resonator used in the 
harvest was long enough and this made it feel less compact. This research is, therefore, focused on replacing the quarter-wavelength with Helmholtz to ensure the AEH device is not as long using the same loudspeaker as before after which the performance was tested.

The construction and testing of an acoustic energy harvester consisting of a cube shape Helmholtz resonator and a subwoofer loudspeaker are described in this article. The objectives were to realize a simple acoustic energy harvester using a loudspeaker as the energy converting component and a Helmholtz resonator as the sound energy collector, and also to determine its performance and operating characteristics in a lowfrequency region. The investigation was, however, conducted with three different lengths of the resonator necks in the frequency region below $200 \mathrm{~Hz}$.

\section{Construction of the acoustic energy harvester}

The acoustic energy harvester used consists of two parts and these include a Helmholtz resonator and a loudspeaker with the terminals connected to a load resistor as shown in Fig. 1 though without the load resistor. It is also important to note that the device was not equipped with an energy storage unit.

The resonator cavity was made with $10 \mathrm{~mm}$-thick cube-shaped acrylic plates with an inner side length of $300 \mathrm{~mm}$ and a hole with $55 \mathrm{~mm}$ diameter was made at the middle of its front wall where a resonator neck produced using PVC (polyvinyl chloride) pipe with an inner diameter of $55 \mathrm{~mm}$ was installed with a $3 \mathrm{~mm}$-thick acrylic flange added to one end of the neck as shown in Fig. 1. The neck was later mounted on the resonator wall with four screws. Three different lengths of the PVC pipes were used including 40, 60 , and $80 \mathrm{~mm}$ and, in addition to the thickness of the resonator wall which was $10 \mathrm{~mm}$, the neck lengths were 50, 70, and $90 \mathrm{~mm}$.

A hole with $147 \mathrm{~mm}$ diameter was made at the middle of the resonator's rear wall to mount the 6-inch C-630-WH model ACR subwoofer used as loudspeaker as shown in Figure 2. This loudspeaker was the same as the one used in the previous study and its resonant frequency was found to be $62 \mathrm{~Hz}$ (Setiawan, 2019) as presented in Figure 3. It was installed facing the resonator cavity to capture the sound waves collected in the cavity and was known in this case as a conversion loudspeaker due to its function as an acoustic transducer which converted sound energy into electric energy. Its terminals were placed outside the cavity and connected to a 100-ohm resistance (R) load resistor. 


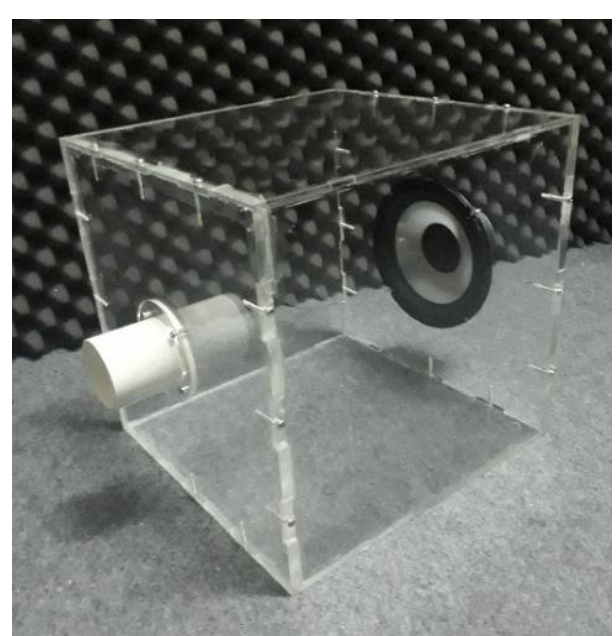

Figure 1. The acoustic energy harvester consisting of a Helmholtz resonator and a loudspeaker

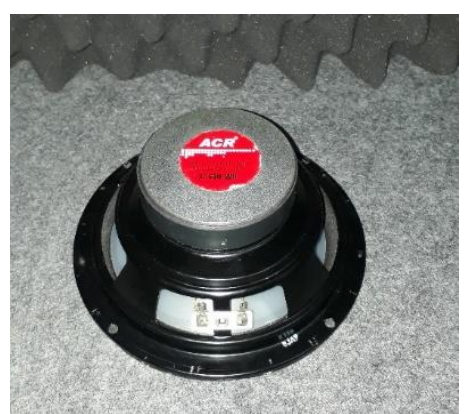

Figure 2. The 6-inch subwoofer loudspeaker

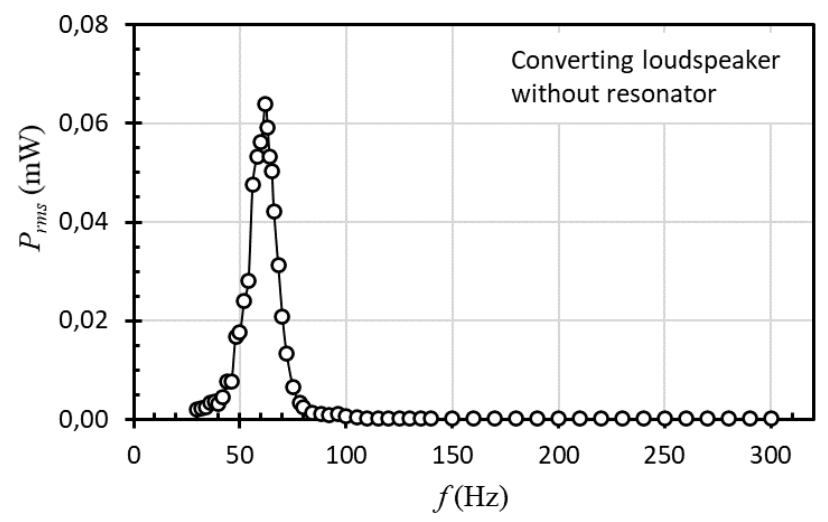

Figure 3. The output rms electric power generated by the converting loudspeaker without resonator under $80 \mathrm{~dB}$ SPL, adapted from reference (Setiawan, 2019)

The fundamental resonant frequency $\left(f_{R}\right)$ of a Helmholtz resonator can be calculated using the lumped element method expressed by (Yuan et al., 2019) as follows

$$
f_{\mathrm{R}}=\frac{v}{2 \pi} \sqrt{\frac{S}{V(l+\gamma r)}}
$$

where $v$ is the sound speed, $S$ is the cross-sectional area of the neck, $l$ is the neck length, $r$ is the neck radius, $\gamma$ is a correction factor (assumed to be 0.82 ), and $V$ is the volume of the resonator cavity. Therefore, based on the assumption that $v=346 \mathrm{~m} / \mathrm{s}$ and the laboratory room temperature was $26{ }^{\circ} \mathrm{C}$, the fundamental resonant frequencies of the Helmholtz resonator with $300 \mathrm{~mm}$ side lengths and neck lengths varied at $50 \mathrm{~mm}, 70$ $\mathrm{mm}$, and $90 \mathrm{~mm}$ were estimated to be $61 \mathrm{~Hz}, 54 \mathrm{~Hz}$, and $49 \mathrm{~Hz}$, respectively. This shows the values are almost the same with the value obtained for the converting loudspeaker. It is, however, important to note that these resonance frequencies were obtained without disturbance from the converting loudspeaker mounted on the rear side of the resonator cavity due to the fact that its presence is capable of altering the values. 


\section{Testing of the acoustic energy harvester}

The acoustic energy harvester was tested using the experimental setup depicted in Figure 4. An Audio Function Generator (AFG) was used to generate a sinusoidal electric signal with adjustable frequencies. The signal was amplified with an audio amplifier and fed into a 15-inch loudspeaker to produce sound waves at a certain frequency and sound level. The sound pressure level (SPL) was measured in decibels (dB) using an SL-4012 model of Lutron SPL-meter with the sensor placed near the resonator neck end. The sound waves entered the Helmholtz resonator through its neck and were converted into an alternating electric current flowing through the load resistor by the conversion loudspeaker at the back wall of the resonator cavity. Moreover, the root-mean-square (rms) voltages across the resistor $\left(V_{r m s}\right)$ were measured using a digital voltmeter to calculate the output rms electric power $\left(P_{r m s}\right)$ using the following equation

$$
P_{r m s}=V_{r m s}^{2} / R
$$

The $V_{r m s}$ and subsequent $P_{r m s}$ were measured for different sound frequencies $(f)$ ranging from $25 \mathrm{~Hz}$ to $200 \mathrm{~Hz}$ with the SPLs varied at $80 \mathrm{~dB}, 90 \mathrm{~dB}$, and $100 \mathrm{~dB}$. These sets of measurements were accomplished for three variations of the neck lengths of the Helmholtz resonator which were $50 \mathrm{~mm}, 70 \mathrm{~mm}$, and $90 \mathrm{~mm}$.

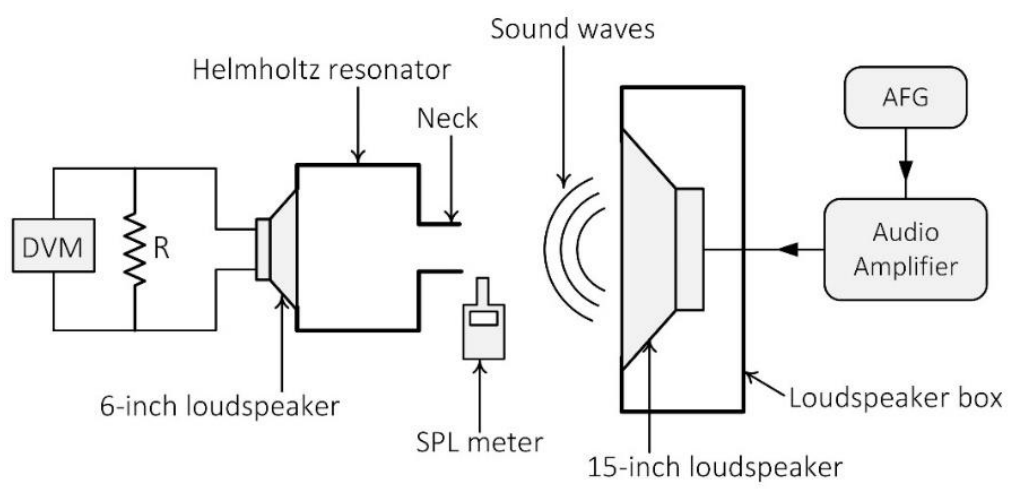

Figure 4. The experimental setup to test the acoustic energy harvester. DVM is a digital voltmeter, $\mathrm{R}$ is a load resistor, and AFG is an audio function generator

\section{Results and Discussion}

The results for three different SPLs of the acoustic energy harvester with $50 \mathrm{~mm}$ length of resonator neck are shown in Figure 5(a) and several peaks were found in the spectrum as indicated from 1 to 7 but not clearly reflected in 3 and 4 . These two peaks are included due to their appearance with the use of longer resonator necks as presented in Figures 5(b) and 5(c). The frequencies at which the peaks appear, together with the rms values of the output electric power generated are listed in Table 1.

The comparison between the shape of the spectrums in Figure 3 for the converting loudspeaker without a resonator and in Figure 5(a) with the resonator mounted showed the installation of the loudspeaker changes the pattern significantly. This is observed with the production of a single peak using converting loudspeaker without resonator compared to the five (or seven) peaks with the resonator and some of those seen in 
Figure 3 no longer appeared in Figure 5. This phenomenon is suspected to be due to a resonance mechanism between the converting loudspeaker and the Helmholtz resonator. The reason for the disappearance of the individual resonance peak for the converting loudspeaker is, however, not known.

Figure 5(a) shows the increase in the SPL from $80 \mathrm{~dB}$ to $90 \mathrm{~dB}$ and $100 \mathrm{~dB}$ produced significant enhancements in the output power but with only a little alteration in the spectrum pattern. For example, the output power in peak number 2 became almost seven times higher with the increase from $80 \mathrm{~dB}$ to $90 \mathrm{~dB}$ and from $90 \mathrm{~dB}$ to $100 \mathrm{~dB}$ as indicated with $0.06 \mathrm{~mW}$ to 0.40 and from 0.40 to $2.75 \mathrm{~mW}$, respectively. Moreover, the highest value was obtained to be $2.75 \mathrm{~mW}$ at $37 \mathrm{~Hz}$ frequency of peak number 2 .
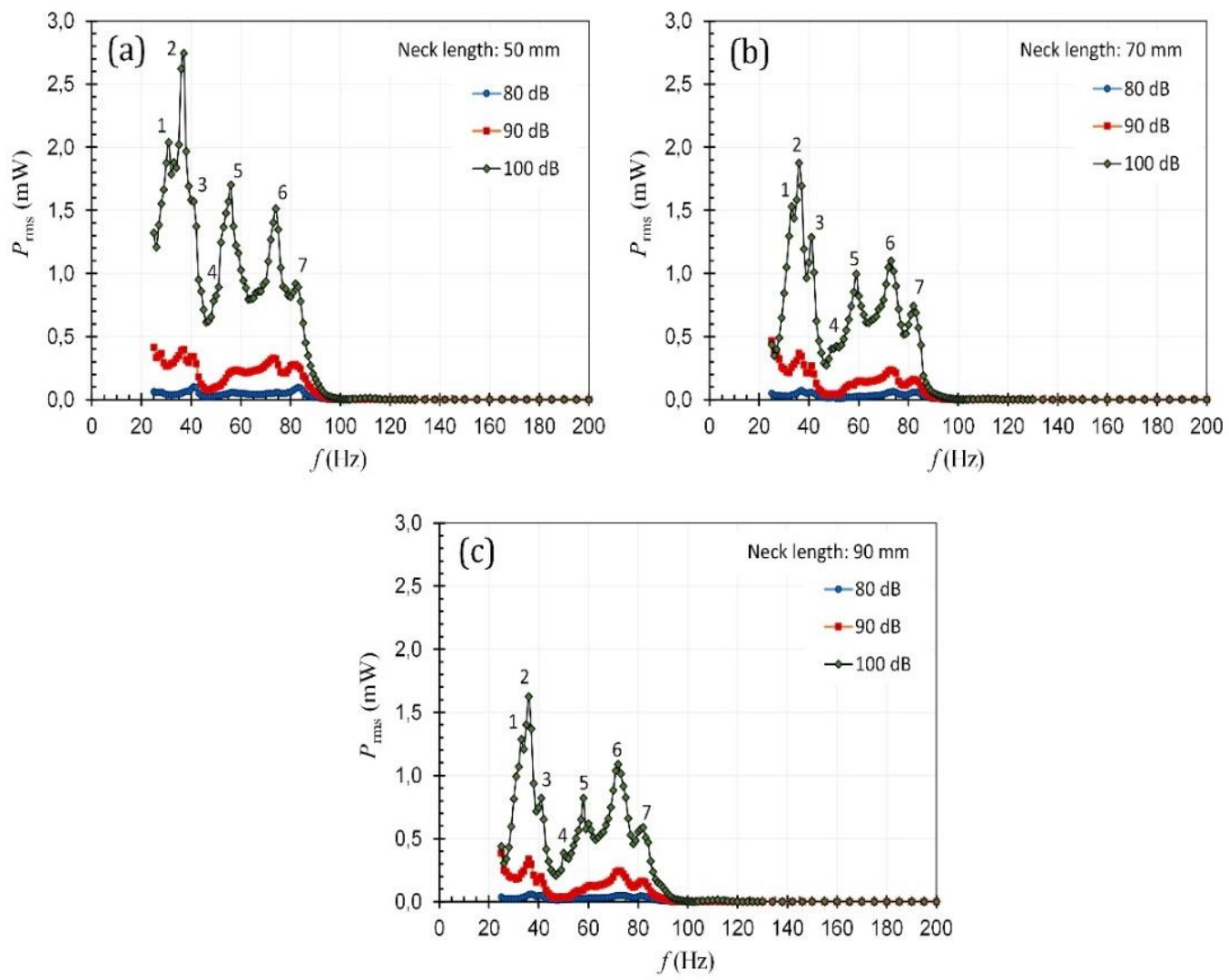

Figure 5. The rms electric power generated by the acoustic energy harvester with a resonator neck length of (a) $50 \mathrm{~mm}$, (b) $70 \mathrm{~mm}$, and (c) $90 \mathrm{~mm}$

Similar results were obtained at $70 \mathrm{~mm}$ and $90 \mathrm{~mm}$ neck lengths having seven spectrum peaks with the highest output power also found in number 2 as shown in Figures 5(b) and 5(c). Moreover, the acoustic energy harvester was observed to generally produced electrical energy in the region of low audio frequency, below 100 $\mathrm{Hz}$, with the possibility of producing zero power above this value. This was the reason the frequency in this experiment was not varied beyond $200 \mathrm{~Hz}$. 
Table 1. Spectrum peaks and output rms electric power obtained in this experiment

\begin{tabular}{ccccccc}
\hline \multirow{2}{*}{$\begin{array}{c}\text { Peak } \\
\text { number }\end{array}$} & \multicolumn{2}{c}{$50 \mathrm{~mm}$ neck } & \multicolumn{2}{c}{$70 \mathrm{~mm}$ neck } & \multicolumn{2}{c}{$90 \mathrm{~mm}$ neck } \\
\cline { 2 - 7 } & $f(\mathrm{~Hz})$ & $P_{\text {rms }}(\mathrm{mW})$ & $f(\mathrm{~Hz})$ & $P_{\text {rms }}(\mathrm{mW})$ & $f(\mathrm{~Hz})$ & $P_{\text {rms }}(\mathrm{mW})$ \\
\hline 1 & 31 & 2.04 & 33 & 1.53 & 33 & 1.29 \\
2 & 37 & 2.75 & 36 & 1.87 & 36 & 1.62 \\
3 & 41 & 1.57 & 41 & 1.29 & 41 & 0.82 \\
\hline 4 & 49 & 0.79 & 49 & 0.41 & 50 & 0.38 \\
5 & 56 & 1.07 & 59 & 1.00 & 58 & 0.82 \\
6 & 74 & 1.51 & 73 & 1.10 & 72 & 1.09 \\
7 & 82 & 0.92 & 82 & 0.74 & 82 & 0.59 \\
\hline
\end{tabular}

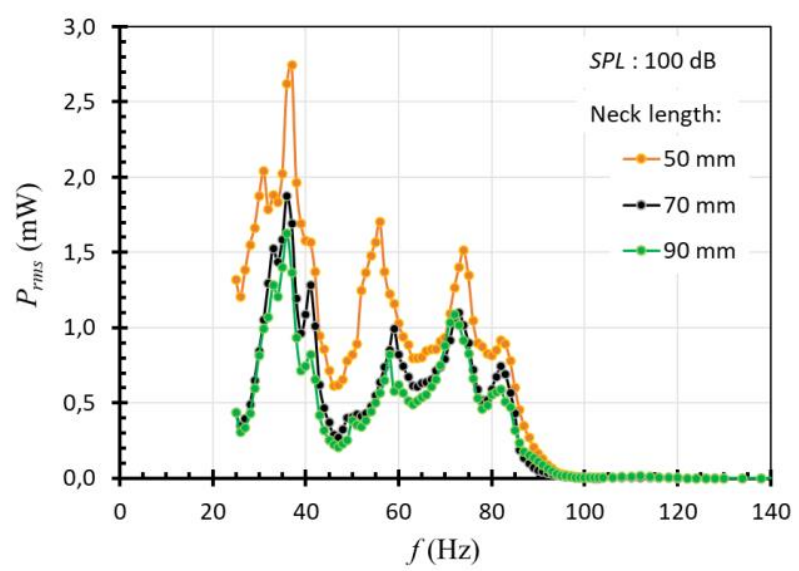

Figure 6. The rms electric power generated by the acoustic energy harvester with different resonator neck lengths exposed by 100-dB SPL sound waves

The distributions of rms electric power produced by the acoustic energy harvester at $50 \mathrm{~mm}, 70 \mathrm{~mm}$, and $90 \mathrm{~mm}$ neck lengths, $100 \mathrm{~dB}$ SPL, and frequencies varied between $25 \mathrm{~Hz}$ and $200 \mathrm{~Hz}$ are plotted together on a graph shown in Figure 6 to ensure easy comparison. All three distributions were discovered to have the same pattern with seven peaks appearing at almost the same frequencies as also indicated in Table 1. The difference, however, lies in the amount of electric power generated. Moreover, the three neck lengths tested showed a shorter resonator neck produced higher electric power as indicated in the bar diagram in Figure 7 which displays the rms values of electric power for each peak of the spectrum for the lengths. The AEH device with a $50 \mathrm{~mm}$ neck length was found to have produced higher electric power than 70 and $90 \mathrm{~mm}$ due to the closeness of its resonator resonance frequency to the values obtained for the converting loudspeaker.

There is a need to optimize the length and diameter of the resonator neck with more variations in the length and diameter for future enhancement of knowledge on the characteristics of the acoustic energy harvester. Moreover, converting loudspeakers with larger diameters would also be necessary to be tested in order to determine the level of the obtainable increase in electric power.

\section{Conclusion}

An acoustic energy harvester consisting of a cube-shaped Helmholtz resonator with $300 \mathrm{~mm}$ side length and a 6-inch subwoofer loudspeaker was successfully constructed 
and tested with good results. The device was able to convert sound energy or noise into electric energy in a low audio frequency region below $100 \mathrm{~Hz}$. The tests conducted by varying the resonators' neck lengths at $50 \mathrm{~mm}, 70 \mathrm{~mm}$, and $90 \mathrm{~mm}$ each with $55 \mathrm{~mm}$ diameter produced frequency spectrums with similar patterns including seven spectrum peaks appearing at almost the same frequencies. The AEH device with a shorter neck was also found to have produced higher electric power while an increase in SPL of the incoming sound waves from $80 \mathrm{~dB}$ to $90 \mathrm{~dB}$ and $100 \mathrm{~dB}$ led to significant improvements in the output electric power with the highest, $2.75 \mathrm{~mW}$, obtained with a $50 \mathrm{~mm}$-long resonator neck, $37 \mathrm{~Hz}$ sound waves frequency, and $100 \mathrm{~dB}$ SPL.

\section{Acknowledgements}

The authors appreciate Mr. Rizky D. Prasetya for assisting during the construction of the Helmholtz resonator. This research was financially supported by Community Funds through Lecturer Research Grant of Faculty of Mathematics and Natural Sciences, Universitas Gadjah Mada, contract number: 0120/J01.1.28/PL.06.02.

\section{References}

Choi, J. I. Jung, and C. Y. Kang. (2009). "A Brief Review of Sound Energy Harvesting," Nano Energy, vol. 56, p.169.

Kang, H. P. Cheng, Z. Yu, and H. Zheng. (2015). "A Two-Stage Traveling-Wave Thermoacoustic Electric Generator with Loudspeakers as Alternators," Appl. Energy, vol. 137, p. 9.

Khan F. U. \& Izhar. (2015). "State of the Art in Acoustic Energy Harvesting," $J$. Micromech. Microeng., vol. 25, p. 023001.

Pillai M. A. \& E. Deenadayalan. (2014). "A Review of Acoustic Energy Harvesting," Int. J. Precis. Eng. Manuf., vol. 15, p. 949.

Setiawan, I. (2019). “Studi Eksperimental Penggunakan Loudspeaker Sebagai Pengkonversi Energi Bunyi Menjadi Listrik Dalam Alat Pemanen Energi Akustik (Acoustic Energy Harvester)," Jurnal Teknologi, vol. 11, p. 9.

Sohn C. H. \& J. H. Park. (2011). "A Comparative Study on Acoustic Damping Induced by Half-Wave, Quarter-Wave, and Helmholtz Resonators," Aerospace Sci. \& Technol., vol. 15, p. 606.

Yu, Z. A. J. Jaworski, and S. Backhaus. (2010). "A Low-Cost Electricity Generator for Rural Areas Using a Traveling-Wave Looped-Tube Thermoacoustic Engine," Proc. IMechE Part A: J. Power and Energy, vol. 224, p. 787.

Yuan, M. Z. Cao, J. Luo, and X. Chuo. (2019). "Recent Developments of Acoustic Energy Harvesting: A review," Micromachines, vol. 10, p. mi10010048.

Zhou, G. L. Huang, W. Li, and Z. Zhu. (2014). "Harvesting Ambient Environmental Energy for Wireless Sensor Networks: A Survey," J. Sensors, vol. 2014, p. 815467. 